Int. J. Electrochem. Sci., 14 (2019) $250-261$

\title{
Preparation of Highly-Active Oxygen Reduction Reaction Catalyst by Direct Co-Pyrolysis of Biomass with KOH
}

\author{
Weimin Cao ${ }^{1, *}$, Bingjia Wang ${ }^{1}$, Yinpan Xia ${ }^{1}$,Wei Zhou ${ }^{1}$, Jia Zhang $^{2}$, Ran Wen $^{2}$, \\ Yi Jia ${ }^{3}$, Qiang Liu $^{2, *}$ \\ ${ }^{1}$ College of Sciences, Shanghai University, No. 99 Shangda Rd., Shanghai 200444, P. R. China \\ ${ }^{2}$ School of Environmental and Chemical Engineering, Shanghai University, No. 333 Nanchen Rd., \\ Shanghai 200444, P. R. China \\ ${ }^{3}$ Queensland Micro- and Nanotechnology Centre, Griffith University, Nathan Campus, Queensland \\ 4111, Australia. \\ *E-mail: cwm213@ staff.shu.edu.cn, qliu@ shu.edu.cn
}

doi: $10.20964 / 2019.01 .33$

Received: 4 September 2018 / Accepted: 18 October 2018 / Published: 30 November 2018

In this work, we developed a cost-effective, facile approach to obtain nitrogen self-doped porous biomass-derived carbon catalyst by direct co-pyrolysis of corn straw biomass with $\mathrm{KOH}$. Through characterization, the obtained catalyst possesses a quite high BET surface area up to $1461.36 \mathrm{~m}^{2} \mathrm{~g}^{-1}$ and significant pyrrolic-N content. Electrochemical test demonstrated that nitrogen self-doped porous carbon exhibits an excellent electrocatalytic activity for oxygen reduction reaction (ORR) in alkaline media, with onset potential of $-0.06 \mathrm{~V}(v s \mathrm{Hg} / \mathrm{HgO})$ and current density of $-3.42 \mathrm{~mA} \mathrm{~cm}^{-2}$, which is comparable to $20 \% \mathrm{Pt} / \mathrm{C}$ catalyst. More importantly, obtained catalyst shows high stability and durability towards ORR reaction. Our results demonstrated that the co-pyrolysis process is a promising route for economical and sustainable utilization of biomass towards the effective metal-free ORR catalysts for alkaline fuel cell.

Keywords: biomass, $\mathrm{KOH}$, ORR catalyst, co-pyrolysis

\section{FULL TEXT}

(C) 2019 The Authors. Published by ESG (www.electrochemsci.org). This article is an open access article distributed under the terms and conditions of the Creative Commons Attribution license (http://creativecommons.org/licenses/by/4.0/). 